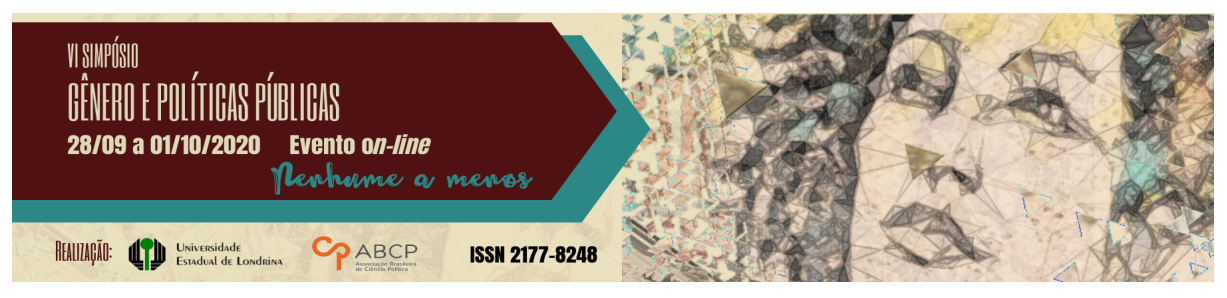

\title{
Implantação do projeto Patrulha Maria da Penha pela Guarda Municipal em um município do interior de São Paulo.
}

\author{
Fábia Suaide ${ }^{1}$; Ana Paula Polacchini de Oliveira²
}

\section{Resumo}

Relato de experiência que tem o objetivo descrever e analisar parcialmente a política pública que visa salvaguardar o direito a integridade física, psicológica e moral das vítimas de violência doméstica em município situado no interior do estado de São Paulo, por intermédio da construção e implantação de parceria formada pelo Tribunal de Justiça do Estado e pela Guarda Civil do município parceiro. As dimensões do trabalho o relato descritivo e analítico da experiência, que considera a análise da legislação, pesquisa empírica, bem como a avaliação de sua eficácia. As ações desenvolvidas pela Patrulha se desenvolvem a partir do acompanhamento e atendimento humanizado das mulheres vítimas de violência doméstica (art. $2^{\circ}$ e configura uma ferramenta de enfrentamento à violência doméstica e também às suas causas.

Palavras-chave: Patrulha Maria da Penha; medidas de proteção; violência doméstica.

\begin{abstract}
Experience report that aims to partially describe and analyze public policy that aims to safeguard the right to physical, psychological and moral integrity of victims of domestic violence in a city located in the interior of the state of São Paulo, through the construction and implementation of a partnership formed by the State Court of Justice and the municipality Civil Guard (Maria da Penha's Patrol).The dimensions of the work are the descriptive and analytical account of the experience, which considers the analysis of the legislation,
\end{abstract}

1 Guarda Civil Municipal de São José do Rio Preto, Bacharel em Direito; fsuaide@gmail.com.

2 Centro Universitário de Rio Preto (UNIRP); Doutora; ana_polacchini@yahoo.com.br.

GT 17 - Policiamento Plural e Dinâmicas de Gênero 
empirical research, as well as the evaluation of its effectiveness. The actions developed by the Maria da Penha's Patrol are developed from the monitoring and humanized care of women victims of domestic violence (article $2^{\circ}$ ) and sets up a tackling domestic violence and its causes.

Key-words: Maria da Penha's Patrol; protective measures; domestic violence

\section{Introdução}

O desenvolvimento do projeto Patrulha Maria da Penha, criado pela lei municipal 13.348/19, que regulamenta o artigo $8^{\circ}$ da lei nacional 11.340 de 07 de agosto de 2006, tem por objetivo salvaguardar o cumprimento das medidas protetivas de urgência aplicadas pelo Tribunal de Justiça do estado de São Paulo, por intermédio do Núcleo de atendimento de violência doméstica (conhecido por anexo), atualmente coordenado pela Juíza titular da $5^{\mathrm{a}}$ vara criminal de São José do Rio Preto. Nesse sentido, a Patrulha foi instituída para que as mulheres contempladas pela mencionada determinação judicial tenham sua integridade física e psicológica garantidas e o gozo seguro de tal deferimento. Para tanto, a previsão é de que a Patrulha promova um tratamento humanitário, protetivo, preventivo e educativo integrado aos demais agentes de proteção e promoção e possa contribuir para inibir a reincidência da agressão, garantindo à agredida segurança na efetividade da medida protetiva. Essas características são fundamentais para contribuir para que não ocorra a revitimização.

A Patrulha tem por pressuposto que seja estabelecido um vínculo de confiança com a vítima, promovendo a proximidade dela à rede de proteção que o município oferece. A violência doméstica tem uma dimensão colonial, estruturada no patriarcado e em outras formas de humilhação. Apesar dos avanços do arcabouço normativo de enfrentamento ao fenômeno, o papel das forças de segurança tem encontrado empecilhos (MELLO; PAIVA, 2019, p.107).

Tendo isso em vista, a Patrulha Maria da Penha promove a divulgação e integração dos órgãos que prestam assistência à mulher 
vítima de violência doméstica através de visitas às mulheres que possuem medida protetiva deferida.

\section{Objetivos}

O relato de experiência decorre de intercâmbio entre academia e comunidade, em um projeto que acompanha a formação e a implantação da Patrulha Maria da Penha pela Guarda Municipal em São José do Rio Preto, município do interior de São Paulo. Dentre os objetivos figuram a i) a descrição objetiva das etapas de implantação da mencionada da lei municipal Lei 13.348/19 que institui o trabalho no município; ii) a identificação do modo como a imprensa local impressa e de radiodifusão abordou esse fenômeno; iii) o relato de como o policiamento feminino pôde contribuir para a implantação e execução do projeto; iv) a adesão das mulheres que receberam a medida de proteção ao trabalho da Patrulha; v) a eficácia da medida no âmbito do enfrentamento à violência contra a mulher.

\section{Metodologia}

As dimensões do trabalho desenvolvido incluem análise da legislação e pesquisa empírica para sistematizar os dados da patrulha e observacional descritiva e social qualitativa, amparadas no referencial teórico e em matriz elaborada a partir das normasaplicáveis.

Quanto à implantação da Patrulha, a metodologia das visitas foi definida após a realização de trabalho preventivo com os órgãos e agentes de enfrentamento à violência doméstica no município, bem como após visitas a municípios que implantaram projetos correlatos. A Guarda Civil Municipal de São José do Rio Preto é uma instituição de segurança pública, pautada nos ideais de servir e proteger e a criação da Patrulha Maria da Penha é um pelotão especializado criado para integrar a Rede de Proteção Municipal à mulher. Para formalizar esse projeto, a Guarda Civil Municipal firmou parceria com o Tribunal de 
Justiça do estado de São Paulo, através do Núcleo de atendimento de violência doméstica (conhecido como Anexo) que presta auxílio às mulheres que procuraram a tutela jurídica, através de uma Portaria em que determina a disponibilização da demanda das medidas protetivas à Patrulha Maria da Penha.

Dentre os parceiros do Tribunal de Justiça estão às universidades que atuam no apoio ao referencial teórico e no auxílio à sistematização de dados do projeto. As demais parcerias incluem a Secretaria da Mulher, que promove no município um trabalho psicológico e assistencial às mulheres que sofrem violência doméstica.

O papel de mulheres atuando na rede e, em especial, na guarda municipal tem atualizado espaços tidos por masculinos e pode ser pensado como uma dimensão de redefinição da própria política. Com a finalidade de colaborar com a integração da Rede de atendimento, promover a divulgação dela e trazer a mulher agredida para os cuidados oferecidos, a Patrulha Maria da Penha, através de visitas periódicas, sempre finalizadas com um relatório onde se reduz a termo toda a situação da vitima de violência após o deferimento da medida. Este relatório, enviado ao Tribunal, tem o intuito de oferecer uma devolutiva a ele no que tange a eficácia da medida.

O projeto teve início em agosto de 2019, quando foi realizado um estudo a viabilidade no município com a intenção de obter um mapeamento da rede de atendimento que São José do Rio Preto ofertava a mulher em situação de violência. Essa pesquisa foi fundamental para a justificativa do trabalho. Integrantes da guarda municipal promoveram visitas às corporações da Guarda Civil de outros municípios que já realizavam o trabalho e que tinham divulgado resultados positivos, tais como o município de Suzano, região metropolitana de São Paulo, e o município de Curitiba- PR, onde foi obtida a capacitação para implantar e operacionalizar o projeto. A capacitação incluiu o entendimento de articulação da rede de atendimento, no que tange a atuação do judiciário, dos cartórios, das 
delegacias especializadas, do Ministério Público, da Defensoria Pública, a atuação da guarda municipal e suas atribuições. De modo geral, trouxe a bagagem necessária para que fosse possível trabalhar a articulação de toda rede. A cidade de Curitiba conta com a Casa da Mulher Brasileira, o que dá um dinamismo e celeridade nas articulações das políticas públicas ali postas. A partir das coletas de informações e com o devido conhecimento em mãos, partiu-se para as adequações do projeto para a realidade do município. O município de São José do Rio Preto possui um aparato de políticas públicas instituído e, apesar de não contar com a referência de enfrentamento à violência tal como a Casa da Mulher Brasileira, conta com equipamentos para garantir a proteção a mulher. Em julho de 2019, foi proposto o projeto de lei n. 121/2019, e convertido em lei no dia 06 de novembro de 2019, com a promulgação da lei ordinária 13.348/2019, que dispõe acerca da atuação da Patrulha Maria da Penha.

Essa lei regulamenta do artigo $8^{\circ}$ da lei nacional 11.340 de 2006 e estabelece as ações da Patrulha Maria da Penha, que se refere à "atuação multidisciplinar dos órgãos municipais competentes para lidar com a demanda de mulheres em situação de violência doméstica e familiar" (artigo $2^{\circ}$ ).

A Convenção para a Eliminação de Todas as Formas de Discriminação contra a Mulher da ONU de 1979 (Convenção CEDAW) confere especialidade ao sistema internacional de proteção de direitos e detalha aspectos indispensáveis ao enfrentamento das desigualdades de gênero.

Por sua vez, o $\S 8^{\circ}$ do artigo 226 da Constituição Federal prescreve o dever estatal em coibir a violência. A lei Maria da Penha, na esteira da Convenção Interamericana para Prevenir, Punir e Erradicar a Violência contra a Mulher de 1994 (Convenção do Belém do Pará) conferem visibilidade e direitos a contextos historicamente reprimidos das mentalidades, cultura e sistema de justiça nacional ainda tomados por ferramentas limitadas. 
Gonçalves (2013, p. 132) explica que a Convenção de Belém do Pará possui um rol abrangente de direitos a serem protegidos, incluindo o direito à integridade física, mental e psicológica, direito de não ser submetida à tortura e direito de liberdade e segurança, direitos estes que são violados cotidianamente. Gonçalves (2013, p. 132) aponta ainda que:

Nesse sentido, nota-se que o Tratado busca definir, por meio de garantia de direitos, estratégias que possam contribuir para alterar a estrutura patriarcal da sociedade, incentivando mudanças culturais e reprimindo discriminações. É uma forma do direito tentar impactar positivamente a sociedade, impulsionado transformações.

Nesse contexto, a lei Maria da Penha sistematiza ferramentas objetivas de enfrentamento a estrutura posta. A articulação do sistema a partir da regulamentação da lei oferece mecanismos para sua implementação. A linha de atuação da Patrulha, conforme estabelece o artigo $3^{\circ}$, inclui:

I - instrumentalização e capacitação da Guarda Municipal no campo de atuação da Lei Maria da Penha, para o correto e eficaz atendimento às mulheres vítimas de violência doméstica e familiar, visando ao atendimento humanizado e qualificado, de acordo com o art. $8^{\circ}$, VII, da Lei Nacional $n^{\circ}$ 11.340, de 7 de agosto de 2006;

II - qualificação do Município no controle, acompanhamento e monitoramento dos casos de violência contra a mulher, de modo a reduzir a incidência desse tipo de ocorrência; e

III - garantia do atendimento humanizado e inclusivo à mulher em situação de violência, especialmente nas hipóteses em que houver medida protetiva de urgência, observado o respeito aos princípios da dignidade da pessoa humana, da não discriminação, da não revitimização, e da corresponsabilidade entre os Entes Federados. 
O decreto municipal 18.553/2020 regulamentou a lei e estabeleceu instituiu o serviço vinculado à Guarda municipal em marco de 2020, delimitou formalmente a estrutura de funcionamento e as ações da Patrulha, desenvolvidas a partir de protocolos de atendimento, definição de normas técnicas e a padronização de fluxos entre os órgãos participantes da Patrulha.

O projeto foi confeccionado com o intuito de especializar o grupamento da Guarda Civil Municipal, a fim de que os integrantes tivessem o perfil específico para a demanda, primando sempre pela conduta mais humanizada nas abordagens.

A rede de atendimento a mulher da cidade sempre foi referência para a região, trazendo consigo uma oferta de amparo muito abrangente. O município conta com a Secretaria da Mulher que promove acompanhamento psicossocial e jurídico, através do CRAM (centro de referência de atendimento à mulher). Esse órgão presta auxílio psicológico, assistencial e jurídico à mulher em situação de violência doméstica. Através desse órgão ocorre o encaminhamento para os demais serviços voltados a proteção e amparo a mulher, como a Casa Abrigo, equipamento onde as mulheres com risco iminente de vida podem ser abrigadas.

A rede saúde, possui protocolos para o atendimento de vítimas de violência, sendo desenvolvidos pelo o CAESM (centro de atendimento especializado na saúde da mulher), voltado para mulheres com depressão pós-parto ou com tendência suicidas e os CAPS (centro de atenção psicossocial), que são voltados a atenção psiquiátrica e saúde mental. O município possui três modalidades de CAPS: i) infantil (crianças e adolescentes até 18 anos), ii) adulto (público em geral), iii) (dependência química - álcool e drogas). Neste último acontece a triagem para a internação em CAPS próprio para acolhimento integral ou para internação em unidade.

Na mesma diretriz, voltada área da assistência, os CRAS (centro de referência de assistência social) enquanto órgãos da secretaria de 
assistência social voltados para a vulnerabilidades e os CREAS (centro de referência especializado da assistência social), para questões de riscos sociais, que vão auxiliar nas demandas assistenciais ofertadas pelo Estado. Versando a esfera da segurança, a Delegacia da Mulher promove uma abordagem mais acolhedora as vítimas, tendo em vista que se volta exclusivamente no atendimento dessa demanda de violência e, buscando essa mesma abordagem.

O projeto Patrulha Maria da Penha tem como princípio a humanização do atendimento, a fim de prevenir a reincidência da agressão, garantir a celeridade no atendimento da vítima em situação emergencial e promover uma relação de confiança entre a vítima e a segurança pública. Por fim, no âmbito jurídico, o município conta com a defensoria pública, o Ministério Público, as universidades que auxiliam nas demandas processuais de violência e com o Núcleo de atendimento de violência doméstica, que se tornou o grande diferencial ao enfrentamento da violência, por ter consigo o condão uniformizar as demandas pertinentes a persecução processual das condutas delitivas que infringem os ditames da Lei11.340/2006.

Diante dessa ampla rede, a mulher vítima de violência ou quem deseje denunciar uma situação de violência tem diversas portas de entrada para a Rede, podendo surgir o chamado de socorro de qualquer braço municipal, tendo em vista que o município trabalha no âmbito de mulheres judicializadas, ou seja, que buscaram a via de entrada pela formalização do boletim de ocorrência e a solicitação de medida protetiva e daquelas que não buscam o judiciário, mas utilizam da Rede para romperem o ciclo da violência.

A Patrulha Maria da Penha iniciou os trabalhos em de março de 2020. A implantação foi antecedida de ampla divulgação e de recorrentes encontros com os integrantes da rede de atendimento e, sobretudo, com a coordenadora do Anexo de violência doméstica, a fim de planejar todo do fluxo de trabalho e o envio de demanda, bem como promover a divulgação do projeto, sempre observando o melhor 
entrosamento entre a Guarda Civil e o Tribunal de Justiça do Estado de São Paulo.

A estrutura da Patrulha conta com comando operacional, encarregado administrativo e patrulheiros em revezamento, com equipes mistas e viaturas de setor. Por ocasião da implantação do serviço a Guarda Civil Municipal passou a receber as demandas do Tribunal de Justiça e, desde então, 470 mulheres foram acompanhadas através de visitas periódicas e acompanhamento via telefones corporativos, o que se mostrou muito eficaz no que se refere a criar vínculo com as assistidas, uma vez que através dele é possível esclarecimentos de dúvidas e envio de ameaças que venham a sofrer. $\mathrm{O}$ acompanhamento é feito de modo consensual, sendo assim, caso alguma vítima não deseje o acompanhamento, ela é desligada do programa e o Tribunal informado.

De março até agosto, através do número emergencial 153, a Guarda Civil Municipal teve um aumento significativo no que tange denúncias e chamados de violência, desse montante, foram realizadas 30 conduções à delegacia da mulher onde os averiguados ficaram à disposição da justiça. Através do grupamento, a Guarda Civil Municipal também promove a localização de agressores para que sejam notificados das medidas protetivas e, por conta da pandemia, foi estabelecido com o Ministério Público um fluxo de atendimento, visando satisfazer a vítima que tenha interesse em declinar de sua medida protetiva. Desse modo, a solicitação é encaminhada ao Ministério Público para análise e manifestação.

A implantação da Patrulha Maria da Penha no município foi, de fato, uma importante estratégia para a construção de políticas públicas voltadas aos direitos da mulher, uma vez que trouxe uma maior integração dentro da rede, a garantia de eficácia da medida protetiva e promoção de segurança de maneira adequada as vítimas.

\section{Resultados alcançados}


A implantação incluiu mais um trabalho voltado para o enfrentamento da violência doméstica, sendo de suma importância para o judiciário, uma vez que, através da Patrulha será possível estabelecer um parâmetro da efetividade e eficácia das medidas protetivas deferidas por ele. Os obstáculos aos feminismos e à atuação política tem encontrado respaldo de enfrentamento pela implantação da guarda (BIROLI, 2018, p. 172).

Para Sabadell, a eficácia de uma medida pode ser aferida a partir dos efeitos sociais, eficácia propriamente dita e pela adequação interna, sendo que fatores instrumentais e sociais podem ser utilizados para essa avaliação (SABADELL, 2017, pp. 56 e 62-65).

Nesse contexto a implantação da Patrulha pode ser avaliada e caminha para satisfazer as expectativas. O projeto está em implantação e passa constantemente pela reflexão sobre aspectos e peculiaridades.

A capacitação dos agentes e a articulação dos envolvidos contribui para a identificação desses fatores. A adesão das vítimas é elemento importante para se pensar o cumprimento da Recomendação 33 do Comitê CEDAW sobre o acesso das mulheres à justiça.

A pauta no trabalho humanitário e preventivo é importante fator que promove capacitação dos agentes envolvidos e o acolhimento da vítima na Rede de Proteção Municipal. Nesse contexto todos dialogam quanto ao enfrentamento do machismo estrutural e demais causas da violência doméstica.

\section{Referências}

BIROLI, Flavia. Gênero e desigualdade: os limites da democracia no Brasil. São Paulo: Boitempo, 2018.

BRASIL. Decreto $n^{0} 1.973$, de 1 de agosto de 1996. Promulga a Convenção Interamericana para Prevenir, Punir e Erradicar a Violência contra a Mulher de 1994. Brasília, DF. Disponível em: <http://www.planalto.gov.br/ccivil_03/decreto/1996/D1973.htm\#: 
:text=DECRETO \%20N\%C2\%BA \%201.973\%2C\%20DE\%201\%C2\%B A,9\%20de\%20junho\%20de\%201994>.

BRASIL. Decreto $n^{0}$ 4.377, de 13 de setembro de 2002. Promulga a Convenção sobre a Eliminação de Todas as Formas de Discriminação contra a Mulher, de 1979. Brasília, DF. Disponível em: <http://www.planalto.gov.br/ccivil_03/decreto/2002/d4377.htm>.

BRASIL. Lei Maria da Penha. Lei no 11.340, de 11 de agosto de 2006. Brasília, DF. Disponível em: <http://www.planalto.gov.br/ccivil_03/_ato20042006/2006/lei/111340.htm>.

GONÇALVES, Tamara Amoroso. Direitos humanos das mulheres $e$ Comissão Interamericana de Direitos Humanos. São Paulo: Saraiva, 2013.

MELLO, Adriana Ramos de; PAIVA, Lívia de Meira Lima. Lei Maria da Penha na prática. São Paulo: Thomson Reuters Brasil, 2019.

SABADELL, Ana Lucia. Manual de sociologia jurídica. 7. ed. rev. atual e ampl. São Paulo: editora Revista dos Tribunais, 2017.

SÃO José do Rio Preto. Lei $n^{o} 13.348$ de 6 de novembro de 2019. Disponível em: https://leismunicipais.com.br/a/sp/s/sao-jose-dorio-preto/lei-ordinaria/2019/1335/13348/lei-ordinaria-n-13348-

2019-regulamenta-a-aplicacao-do-art-8-da-lei-nacional-n-11340-de-7de- agosto-de-2006-no-mbito-do-municipio-de-sao-jose-do-rio-pretodispondo-acerca-da-atuacao-da-patrulha-maria-da-penha-e-daoutras-providencias?q=13348.

SÃO José do Rio Preto. Decreto 18.553 de 20 de março de 2020. Jornal D'hoje.

Disponível em: <http:/ / proposicoes.saojosedoriopreto.sp.leg.br/arquivo?Id=42379> 